\title{
Neonatal thrombocytopenia: A review. I. Definitions, differential diagnosis, causes, immune thrombocytopenia
}

\author{
Hugo Donato, M.D. ${ }^{a}$
}

\begin{abstract}
Thrombocytopenia, defined as a platelet count below $100 \times 10^{9} / \mathrm{L}$, is a very common finding in the neonatal period, especially in critically ill infants and preterm newborns. Its causes are multiple: it may be due both to pediatric conditions and to other factors involved in the fetal-placental-maternal interface. This initial article describes the causes of thrombocytopenia, proposes a diagnostic approach to manage a thrombocytopenic newborn infant, and provides a detailed description of the different conditions corresponding to thrombocytopenia of immune etiology. It also describes the different causative mechanisms and reviews the varying characteristics of thrombocytopenia secondary to maternal immune thrombocytopenia and neonatal alloimmune thrombocytopenia. The different treatment approaches to each of the different conditions are described both for their pre- as well as their postnatal management. The severity of thrombocytopenia and the serious complications and sequelae associated with the neonatal alloimmune thrombocytopenia are highlighted.

Key words: neonatal thrombocytopenia, immune thrombocytopenia, thrombocytopenic purpura, neonatal alloimmune thrombocytopenia, platelet transfusion.
\end{abstract}

http:/ / dx.doi.org/10.5546/ aap.2021.eng.e202

To cite: Donato H. Neonatal thrombocytopenia: A review. I. Definitions, differential diagnosis, causes, immune thrombocytopenias. Arch Argent Pediatr 2021;119(3):e202-e214.

a. Private Outpatient Pediatric Hematology Offices. Autonomous City of Buenos Aires, Argentina.

E-mail address:

Hugo Donato, M.D.: hcdonato@gmail.com

Funding:

None.

Conflict of interest:

None.

Received: 8-27-2020

Accepted: 10-30-2020

\section{GLOSSARY}

IPF: immature platelet fraction.

IT: immune thrombocytopenia.

IVIG: intravenous immunoglobulin G.

NAIT: neonatal alloimmune thrombocytopenia.

PC: platelet count.

SLE: systemic lupus erythematosus.

\section{INTRODUCTION}

Thrombocytopenia is a very common finding in the neonatal period, especially in critically ill and preterm newborn infants (NBIs). It is present in 1-5\% of babies at birth $^{1-4}$ and in $20-50 \%$ of critically ill newborns. ${ }^{5,6}$

A prospective study with 807 hospitalized NBIs found severe thrombocytopenia in $20 \%$ of subjects. ${ }^{6}$ A similar study reported that thrombocytopenia was much more common among preterm (18.2\%) than term infants $(0.8 \%))^{7}$ It is worth noting that there is no direct relationship between severe thrombocytopenia and the occurrence of bleeding events. ${ }^{8-13}$ In an observational study, bleeding was observed only in $9 \%$ of NBIs with severe thrombocytopenia. ${ }^{10}$

Given its high rate of occurrence and the severity of potential adverse effects, platelets should be assessed not only in any child with bleeding but also as a routine test in all critically ill NBIs as well as in healthy ones with a family history of thrombocytopenia. Its causes are multiple: it may be due both to pediatric conditions and to other factors involved in the fetalplacental-maternal interface.

\section{DEFINITIONS}

The current definition of thrombocytopenia, at any age, is a platelet count (PC) below $100 \times 10^{9} / \mathrm{L}^{14}$ This is also applicable to NBIs since different studies have reported that a small percentage (approximately $4 \%$ ) of normal NBIs had values between 100 and $150 \times 10^{9} / \mathrm{L}^{15-17} \mathrm{~A}$ PC below $50 \times 10^{9} / \mathrm{L}$ is considered severe, which occurs in $0.1-0.5 \%$ of cases. ${ }^{3,4,18}$ 


\section{CAUSES AND DIFFERENTIAL DIAGNOSIS}

Causes of neonatal thrombocytopenia are multiple and can be classified in several ways. The most convenient is according to the mechanism producing thrombocytopenia, either as a result of increased destruction or decreased synthesis (Table 1).
The diagnostic assessment of a thrombocytopenic NBI is essentially based on the baby's history and clinical status. As is the case of many other conditions in this period of life, thrombocytopenia may be the result of neonatal diseases as well as other factors involved in the fetal-placental-maternal interface

TABLE 1. Causes of thrombocytopenia

DUE TO INCREASED DESTRUCTION

Immune cause

Due to autoantibodies (secondary to a maternal condition):

Immune thrombocytopenia (IT)

Primary

Associated with

Systemic lupus erythematosus

Human immunodeficiency virus infection

Drugs

Due to alloantibodies

Neonatal alloimmune thrombocytopenia

\section{Non-immune cause}

Intrauterine infection

Giant hemangioma

Severe hyperbilirubinemia

Severe hemolytic disease of the newborn

Polycythemia-hyperviscosity syndrome

Hypersplenism

Thrombotic microangiopathy

Disseminated intravascular coagulation

Thrombotic thrombocytopenic purpura

Atypical hemolytic uremic syndrome

\section{DUE TO DECREASED PRODUCTION}

Due to bone marrow replacement or occupation

Congenital leukemia

Transient myeloproliferative disorder

Osteopetrosis

Neuroblastoma

Langerhans cell histiocytosis

Due to bone marrow failure

Intrauterine infection

Inherited thrombocytopenia

Amegakaryocytic thrombocytopenia

Congenital amegakaryocytic thrombocytopenia

Amegakaryocytic thrombocytopenia with absent radii

Amegakaryocytic thrombocytopenia with radio-ulnar synostosis

Fanconi anemia

Other inherited bone marrow failure

DUE TO MIXED OR UNKNOWN MECHANISM

Perinatal infection

Necrotizing enterocolitis

Intrauterine infection

Neonatal respiratory disorder

Hyaline membrane disease

Perinatal asphyxia

Neonatal aspiration syndrome

Intrauterine growth restriction

Inherited metabolic disorder

Chromosomal abnormalities

Secondary to maternal conditions

Arterial hypertension

Hyperthyroidism 
(Figure 1). Therefore, consideration should be given not only to the current condition, but also to the procedures the NBI has undergone or is undergoing, the effect of maternal current or past conditions, and the gestational and obstetric history elicited during the history taking.

The first thing to take into account is the patient's clinical status because management will vary radically whether the baby is healthy or critically ill. The most probable diagnoses to consider are shown in Table 2. Another aspect to be evaluated is the onset of thrombocytopenia. Roberts and Murray have distinguished three groups, based on the most common causes: a) Intrauterine onset: immune thrombocytopenia, intrauterine infection, chromosomal abnormalities; b) Early onset (less than 72 hours of life): placental insufficiency, perinatal asphyxia, perinatal infection, immune thrombocytopenia, disseminated intravascular coagulation; c) Late onset (more than 72 hours of life): late-onset sepsis, necrotizing enterocolitis, amegakaryocytic thrombocytopenia, giant hemangioma. ${ }^{19}$

Supplementary lab tests provide few significant data in the initial assessment. In general, mean platelet volume (MPV) is a useful parameter to differentiate between thrombocytopenia resulting from increased destruction or from a synthesis defect.

By combining these data with PC, Christensen et al. have proposed the concept of "platelet mass" for a better indication of platelet transfusion in neonates. ${ }^{20}$ The immature platelet fraction (IPF) has been introduced in modern cell counters and is very useful to differentiate between synthesis defect and increased destruction as causative mechanisms of thrombocytopenia and, in recent years, its use has also been confirmed in NBIs. ${ }^{21-23}$

Other tests should be reserved mainly to confirm some presumptive diagnoses,

FIGURE 1. Effect of perinatal factors on platelets

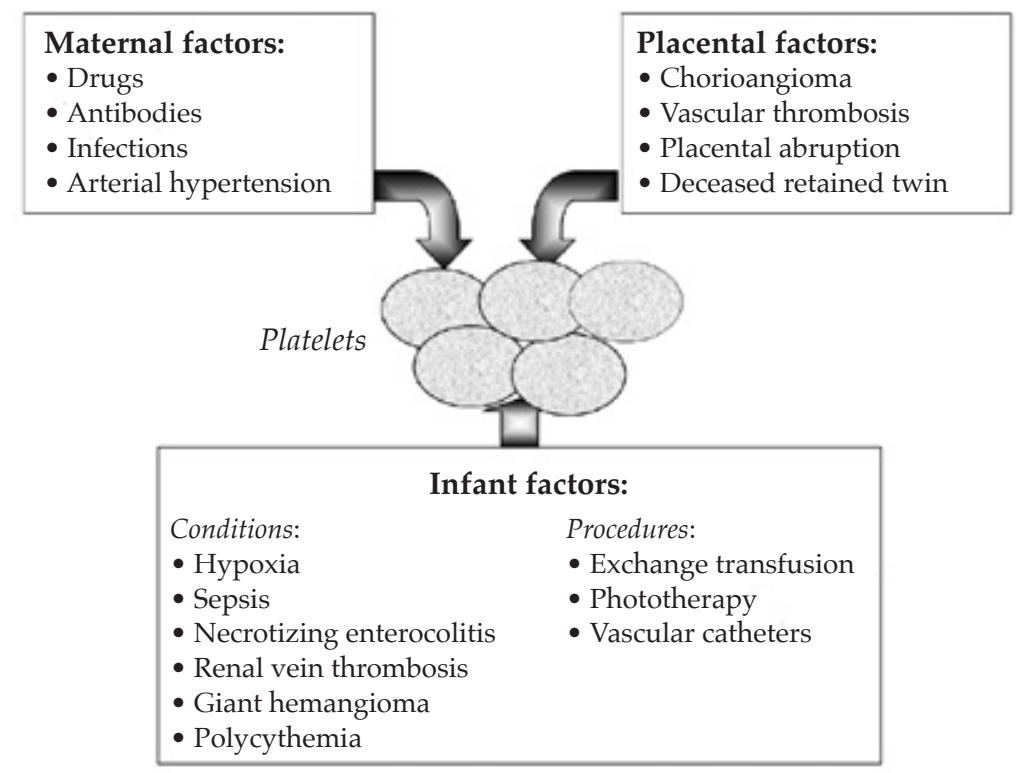

Source: Developed by the author.

TABLE 2. Likely causes of thrombocytopenia based on clinical status

\begin{tabular}{cc}
\hline Healthy & Sick \\
\hline Immune thrombocytopenia & Perinatal infection \\
Inherited thrombocytopenia & Intrauterine infection \\
Amegakaryocytic thrombocytopenia & Necrotizing enterocolitis \\
Giant hemangioma & Disseminated intravascular coagulation \\
Maternal conditions & Respiratory disorder \\
Other & Other \\
\hline
\end{tabular}


such as platelet antigen levels in alloimmune thrombocytopenia, chromosomal testing in aneuploidy, genetic testing in inherited thrombocytopenia, or bone marrow biopsy in amegakaryocytic thrombocytopenia.

\section{IMMUNE THROMBOCYTOPENIA}

Transplacental passage of antibodies from the pregnant woman to the fetus may cause transient thrombocytopenia in the NBI. Depending on the antibody, there are two types of thrombocytopenia (Figure 2): a) Autoantibodies: they are directed against a maternal platelet antigen, and the fetus is the passive subject of a maternal condition that causes thrombocytopenia; b) Alloantibodies: they are directed against a fetal platelet antigen that is absent in the maternal platelets, and the fetus is the active subject suffering the sequelae of antibodies produced by the platelets of their healthy mother.

\section{Thrombocytopenia caused by autoantibodies}

The maternal condition in which this disorder most frequently occurs is primary immune thrombocytopenia (IT), but it may potentially occur in any other autoimmune disease. The actual incidence of thrombocytopenia among NBIs from mothers with IT has not been clearly established yet because, according to published studies, it ranges from $16 \%$ to $56 \% .{ }^{24-31}$ Considering that, a PC of $50 \times 10^{9} / \mathrm{L}$ has been defined as safe in NBIs, even in sick and preterm babies, there is an overwhelming consensus that a PC below
$50 \times 10^{9} / \mathrm{L}$ is considered severe thrombocytopenia, which occurs in $8-11 \%$ of NBIs from mothers with IT. $8,11,12,18,19,32$

This disorder occurs both in NBIs from mothers with active IT diagnosed before or during pregnancy and in those in whom it has apparently resolved, either due to spontaneous remission or splenectomy (Figure 3 ). In the latter case, many times, it may be explained by the fact that, although the basic mechanism leading to autoimmunity is not eliminated, the body manages to reach a balanced status between platelet destruction and production ("compensated thrombocytolitic state"), which allows PC to remain constantly within normal ranges, in spite of persistent circulating antiplatelet autoantibodies. ${ }^{33,34}$

For this reason, the treating obstetrician should prioritize the history of IT in the mother, regardless of the time elapsed since an apparent resolution (relapses have been reported up to 22 years after remission), and warn the neonatologist. It is important to note that in the case of a NBI with thrombocytopenia this diagnosis should always be taken into consideration, even without a known maternal history because, sometimes, maternal IT may only be diagnosed after a thrombocytopenic baby is born. ${ }^{35}$ Several studies have failed to define some characteristics of maternal IT that would help to predict the newborn's PC at birth. No correlation has been established between this and other maternal factors, such as PC, antibody levels, or

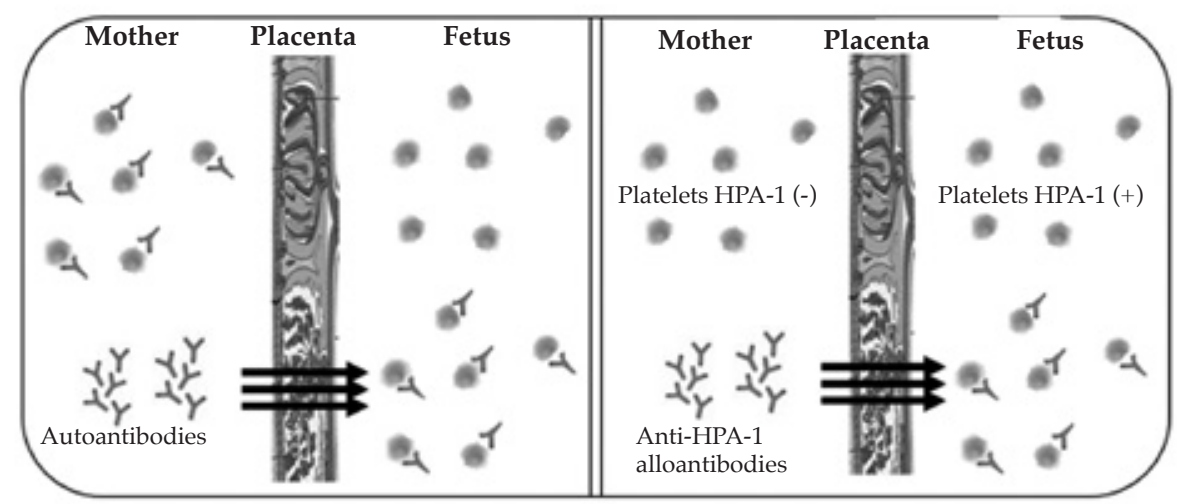

(a)

(b)

(a) Anti-platelet membrane glycoprotein (e.g., IIb/IIIa) autoantibodies cross the placenta and bind to fetal platelets;

(b) Antibodies against a platelet antigen absent from maternal platelets (e.g., HPA-1), which exist naturally, cross the placenta and bind to fetal platelets positive for such antigen. 
a history of splenectomy. $32,36,37$

In a retrospective study, mothers were divided into two groups, depending on whether they reached a PC $<50 \times 10^{9} / \mathrm{L}(\mathrm{n}=41)$ or $\geq 50 \times 10^{9} / \mathrm{L}$ $(n=67)$ during pregnancy, and it was observed that there were no significant differences between the NBIs in both groups in terms of PC at birth $\left(192 \times 10^{9} / \mathrm{L}\right.$ versus $157 \times 10^{9} / \mathrm{L}$, respectively $)$, a lower PC in the NBI $\left(142 \times 10^{9} / \mathrm{L}\right.$ versus $143 \times 10^{9} / \mathrm{L}$, respectively) or the number of NBIs with a $\mathrm{PC}<142 \times 10^{9} / \mathrm{L}$ at birth $(19.5 \%$ versus $11.9 \%$, respectively). ${ }^{31}$

Nowadays, only a prior history of severe neonatal thrombocytopenia in a sibling is considered a major predictor. ${ }^{38-42}$ However, in this disease, the lowest PC sometimes does not occur in the first 24 hours, but only 3-5 days after birth. ${ }^{31,33,39,43}$ In a review of 119 pregnancies of women with IT,
Webert et al. observed an incidence of $10.1 \%$ of $\mathrm{PC}<50 \times 10^{9} / \mathrm{L}$ in cord blood, but, in the follow-up of these NBIs, $16.6 \%$ had reached a PC $<50 \times 10^{9} / \mathrm{L}$ at some point in their first 2 weeks of life. ${ }^{31}$ Other studies reported higher rates (24\% to $30 \%$ ) of severe thrombocytopenia during this period. ${ }^{39,44}$

In symptomatic NBIs, bleeding is usually mild to moderate. The most common types of bleeding include petechiae, bruises, epistaxis, melena, hematuria, cephalohematoma, umbilical cord bleeding, and bleeding from venipuncture sites. The frequency of severe bleeding (basically intracranial) is low. Although it has been reported in up to $4 \%$ of cases, ${ }^{25,27}$ most authors agree its incidence is below $1 \% .18,29,31,38,45$ Thrombocytopenia may persist up to 4 months old, but the risk for bleeding practically disappears after 2 weeks of life. ${ }^{35}$

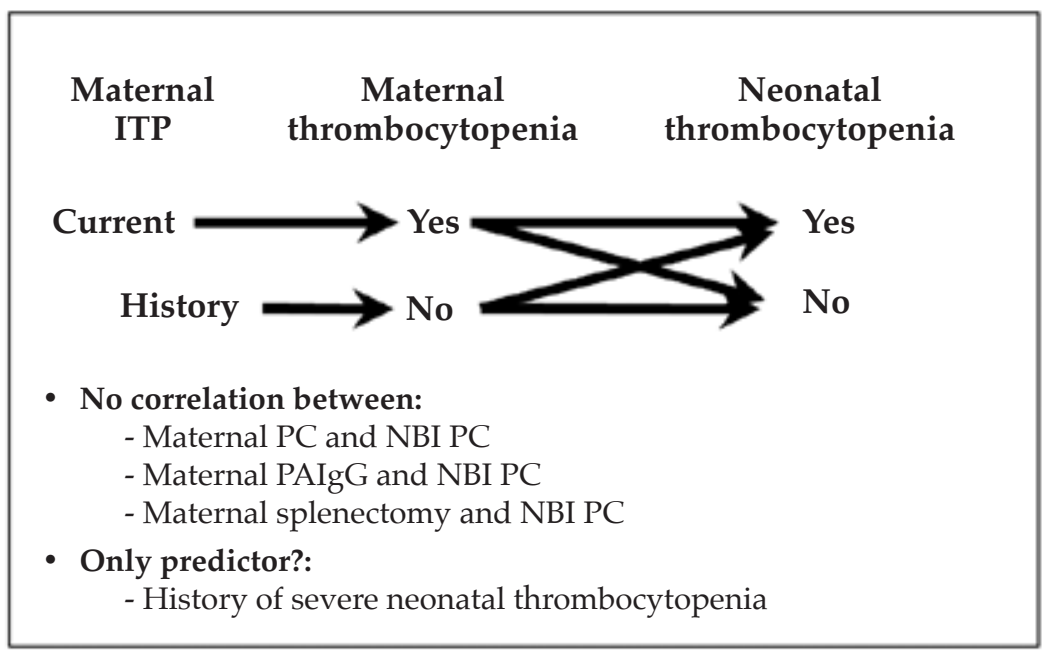

Both NBIs from a mother with active IT and those from a mother with a history of IT may or may not develop neonatal thrombocytopenia. There is no correlation between the maternal platelet count, the level of membrane-bound and platelet-associated IgG (PAIgG) or the history of splenectomy, and the occurrence or not of thrombocytopenia. The only predictor seems to be the history of severe thrombocytopenia in a previous sibling.

TABLE 3. Therapeutic approach in newborn infants born from mothers with immune thrombocytopenia

Postnatal management

- Platelet count $>30 \times 10^{9} / \mathrm{L}$ :

- Expectant management and control 1-2 times a day for 7 days

- Platelet count $<30 \times 10^{9} / \mathrm{L}$ :

- Intravenous immunoglobulin G. $1 \mathrm{~g} / \mathrm{kg} /$ day for $1-2$ days

- Exchange transfusion + irradiated platelet transfusion

- Anti-D immunoglobulin (?)

- Corticosteroids (?)

Antenatal management

- Detection of fetal thrombocytopenia (cordocentesis or scalp sampling)

- Very-high-dose intravenous immunoglobulin G administered to the pregnant woman 
The decision whether to treat or not a thrombocytopenic NBI is based, among other factors, on PC, bleeding signs, and the eventual need for an interventional procedure. ${ }^{31}$ However, to date, there are no evidence-based guidelines for the management of these cases. The most convenient management is shown in Table 3. The treatment of choice with intravenous immunoglobulin G (IVIG), alone or in association with platelet transfusion, has been successful in $80-90 \%$ of cases. ${ }^{12,31,46-49}$ High dose IVIG, by way of a competition mechanism, leads to the blocking of Fc receptors in reticuloendothelial system cells, thus preventing antibody-coated platelets from binding to them for destruction (Figure 4). If there is no IVIG available, an exchange transfusion combined with platelet transfusion should be performed. ${ }^{35,50}$

Corticosteroids are still mentioned by some authors as a treatment alternative, but there is no evidence to confirm their effectiveness. Anti-D immunoglobulin is widely used in the management of infant IT because it also blocks receptors, in this case, due to the massive uptake of anti-D-antibody-coated red blood cells. Isolated cases of successful use in NBIs from mothers with IT have been reported..$^{51,52}$ Since its administration is associated with mild to moderate hemolysis, it should not be considered the first line of treatment in NBIs, but only as an alternative approach when other treatments are not available or have failed.

Antenatal interventions have also been attempted. Methods to detect thrombocytopenia in the fetus have been successful in some cases, ${ }^{53,54}$ but most authors have not been able to replicate them. The high morbidity and mortality of cordocentesis (1\%), practically equal to thrombocytopenia mortality rate, has discouraged it routine use, as well as the high rate of false low PC values obtained by scalp sampling. ${ }^{37,55-59}$ The administration of high dose IVIG before delivery in an attempt to improve fetal thrombocytopenia has shown very controversial results, so it is not currently recommended. ${ }^{37}$

The selection of the most adequate obstetric management for delivery (vaginal or elective C-section) is a difficult issue, and the risks and benefits for both the baby and the mother should be weighted. Considering that there are practically no definite predictors to establish the true risk for the NBI to develop severe thrombocytopenia, and based on the low perinatal mortality, most authors agree that there is no evidence that a C-section would be safer for the baby than a vaginal delivery. ${ }^{38,49,60-62}$ However, as

FIGURE 4. Mechanism of action of intravenous immunoglobulin $G$ in the infant from a mother with immune thrombocytopenia

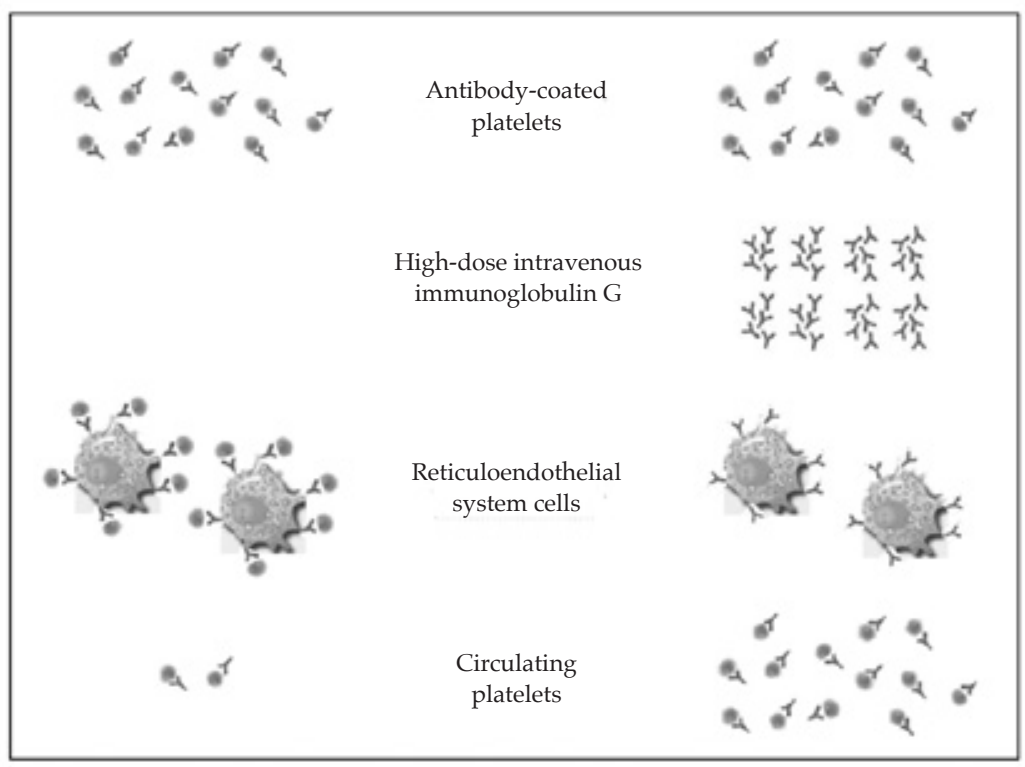

Immunoglobulin $\mathrm{G}$ competes for Fc receptors in reticuloendothelial system cells with antibodies bound to the platelet membrane, leading to the saturation of such receptors. As a result, the number of platelets captured by macrophages is reduced, leading to an increase in the number of circulating platelets.

Source: Developed by the author. 
most of the evidence supporting this conclusion comes from retrospective studies, this issue is still controversial, and results of prospective multicenter studies should be obtained to find a definite answer to this question.

Autoimmune thrombocytopenia may also occur in the NBIs from mothers with IT associated with other maternal conditions ${ }^{63}$ It is uncommon in systemic lupus erythematosus (SLE). In a review of 55 cases of mothers with SLE, Burrows and Kelton reported that only 8 NBIs (14.5\%) developed thrombocytopenia, which was mild (PC between 50 and $150 \times 10^{9} / \mathrm{L}$ ) in all cases. ${ }^{18}$ Thrombocytopenia may also be the initial, single manifestation of neonatal SLE, ${ }^{64,65}$ a syndrome characterized by congenital atrioventricular block, skin lesions, and blood disorders. ${ }^{66,67}$

It has been reported that mothers with IT associated with human immunodeficiency virus (HIV) have also delivered thrombocytopenic babies. ${ }^{68}$ In the case of IT associated with maternal drug use (quinines, sulfonamides, thiazides, methyldopa, ampicillin, cephalexin, meprobamate, etc.), the baby may be born with thrombocytopenia, but very few cases have been truly confirmed. ${ }^{33,35,69,70}$ The treatment in all these cases is the same as for primary IT.

\section{Thrombocytopenia caused by alloantibodies \\ Neonatal alloimmune thrombocytopenia} (NAIT) is the major cause of thrombocytopenia among healthy term NBIs. Its incidence is 1 every 1000-2000 births, although it may be higher. , 3,318,71-76 $^{2}$ It is reported in 40-50\% of firstborns. ${ }^{73,77-79}$ It is caused by an immune mechanism of incompatibility between maternal and fetal platelet antigens, similar to what happens with erythrocyte antigens in hemolytic disease due to blood group incompatibility: a pregnant woman exposed to a platelet surface antigen she lacks will develop antibodies against it, which will cross the placenta and lead to the destruction of fetal platelets expressing such antigen. ${ }^{80-84}$ In some cases, a simultaneous suppression of megakaryocytopoiesis may also occur. ${ }^{85-87}$

The results of a Norwegian screening study demonstrated that maternal sensitization occurs in most cases during delivery or immediately after it. ${ }^{88}$ Any platelet antigen may be involved in this disorder, but human platelet antigen (HPA) $1 \mathrm{a}$, which is present in more than $90 \%$ of the population, is accountable for most cases, followed by HPA-3 and HPA-5. ${ }^{37,73,89-91}$ Among HPA-1a-negative women, the possibility of developing immunization is mainly associated with human leukocyte antigen (HLA) DRB3 ${ }^{*} 0101$.

The typical presentation is an infant with moderate to severe thrombocytopenia who develops bleeding into the skin and / or other sites, with no other symptoms, born from a healthy mother without thrombocytopenia or a history of thrombocytopenia, delivered unremarkably. In general, clinical manifestations occur earlier and are more severe than those observed in thrombocytopenia caused by autoantibodies. ${ }^{35}$ The PC is usually below $30 \times 10^{9} / \mathrm{L}$. Bleeding may occur at any site, but the incidence of intracranial hemorrhage is high: it has been reported in 10-30 \% of affected NBIs. ${ }^{73,84,90,92-96}$ It has been estimated that it develops in utero, which may sometimes lead to porencephaly or hydrocephalus. ${ }^{73,92,96-99}$ Morbidity and mortality are high; the mortality rate has been reported to be $12-14 \%$ without treatment. ${ }^{77}$ Among NBIs with intracranial hemorrhage, $25 \%$ of them will have major neurological sequelae, ${ }^{90,94,95,99,100}$ although the prognosis is better among those who received intensive antenatal treatment. ${ }^{101,102}$ Establishing maternal antibody levels in the blood during the third trimester appears to be an indicator of disease severity. ${ }^{103}$

Clinically more severe cases are caused by HPA-1a. There are many potential explanations for this observation, but the most feasible one seems to be related to the antigen location in the GPIIb / IIIa complex. ${ }^{37}$ It has been proposed that such location would allow the following: a) since it is the most abundant platelet glycoprotein, alloantibody sensitization would lead to a more severe destruction; $b$ ) since it is the binding site where fibrinogen binds to platelets, it may cause a decreased platelet aggregability; c) since the vascular endothelium contains a IIIa-like glycoprotein, alloantibodies may bind to it and cause endothelial damage. Given the severity of the disease, a definitive diagnosis should be made as soon as possible to quickly establish the most adequate treatment approach. ${ }^{91,96,104,105}$ Confirmation requires genotyping to determine platelet antigen incompatibility and the identification of the alloantibody in the mother and / or the baby. ${ }^{91,105}$ Different methods are being studied to establish which one is most accurate. ${ }^{91,106,107}$ Since results take no less than 2-3 days, it is justified to start treatment empirically if the suspicion is strong. ${ }^{106,107}$ Treatment options are shown in Table 4. Maternal or antigen-compatible platelet transfusion, 
washed and irradiated, is the treatment of choice because the mothers lack the affected platelet antigen. . $^{37,90,91,104,105,108-114} \mathrm{In}$ addition, it is a very good option to do a therapeutic test when it is not possible to confirm diagnosis because, in this case, transfused platelets are not destroyed during circulation, thus allowing the NBI to maintain a safe PC. ${ }^{109,115-117}$ The transfusion of blood bank platelets, whether or not associated with IVIG, is relatively effective because the probability of administering platelets positive for the responsible antigen is greater than $90 \%$, but it can achieve partial and short-lasting responses that may be useful in some cases. ${ }^{90,91,104,105,112-114,118,119}$

Recently, a PC-based algorithm and the presence or absence of bleeding has been proposed by a task force for the indication of platelet transfusion, but it has not been validated in prospective studies. ${ }^{120}$ If platelet units are not available, IVIG ${ }^{119,121}$ is an option with the same mechanism described for autoimmune thrombocytopenia. Corticosteroids have not proven effective. ${ }^{77,122}$ Studies with different antiplatelet antigen monoclonal antibodies have reported promising results, but their ease of use in the daily practice is still under study. ${ }^{123-127}$ Given the severity of the disease, most authors recommend doing a C-section. . $^{84,128,129}$

Once a NBI has developed NAIT, the risk for subsequent children will also be affected is $50 \%$ among heterozygous parents and almost $100 \%$ among homozygous ones. ${ }^{89,130-132}$ For this reason, several antenatal interventions have been proposed to prevent severe thrombocytopenia among NBIs with an older sibling who has been affected. Intrauterine transfusion of maternal platelets is useful, but carries a fetal-loss risk of $1.3 \%$ per transfusion, so that the accumulation of transfusions by weekly administration brings the total risk to $8.3 \%$, thus limiting its use to a great extent. $^{87,133-137}$

Currently, the treatment of choice is the

TABLE 4. Therapeutic approach in children with neonatal alloimmune thrombocytopenia

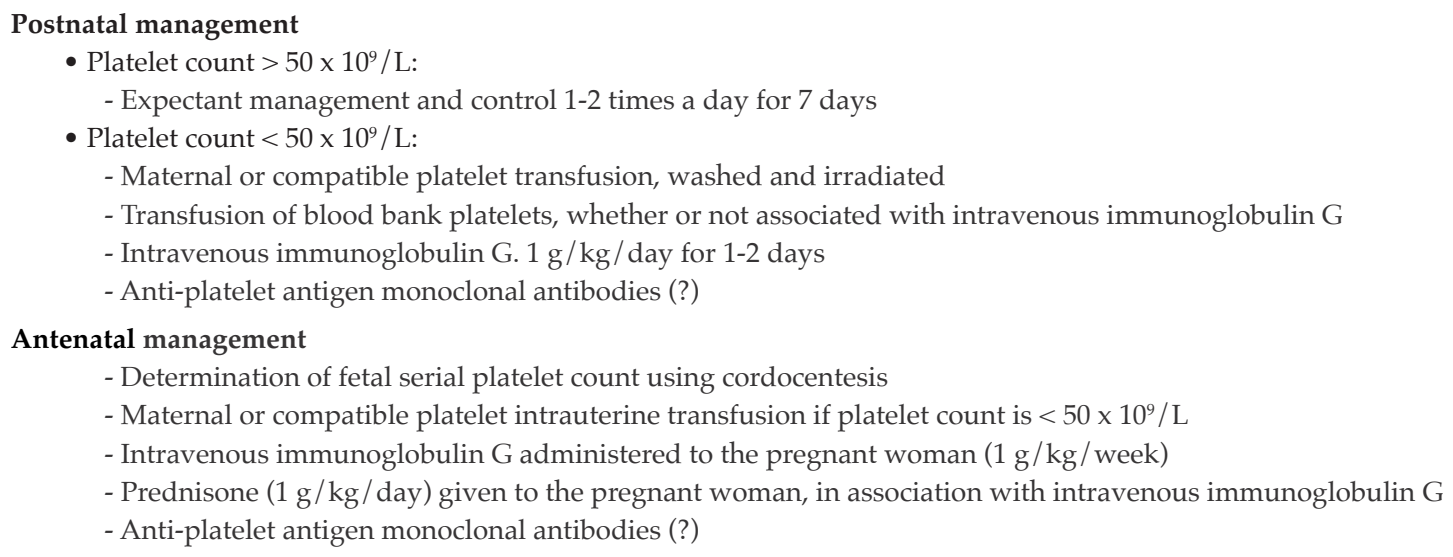

TABLE 5. Summary of the most relevant aspects of neonatal alloimmune thrombocytopenia

- It is a severe condition that often leads to major neurological sequelae.

- In general, it occurs in all NBIs who carry the antigen.

- Diagnosis should be fast enough to establish the management.

- If diagnosis is presumptive and cannot be confirmed, the initiation of an empiric treatment is warranted.

- The most common type of alloimmunization is the human platelet antigen (HPA)-1a.

- Women negative for HPA-1a and positive for HLA DRB3*0101 are at high risk, so they should be referred for antenatal diagnosis and follow-up.

- Brain damage severity warrants antenatal diagnosis and treatment among high-risk mothers.

- A fetus with thrombocytopenia may benefit from intrauterine platelet transfusion.

- A fetus with thrombocytopenia should be delivered by C-section. 
administration of weekly IVIG doses to the pregnant woman, whether associated or not with corticosteroids. ${ }^{112,134-136,138-146}$ The immediate administration of anti-HPA-1a monoclonal antibodies after delivery to prevent maternal sensitization is under study. ${ }^{124,127}$ Different systems have also been proposed to determine risk groups in order to define a customized antenatal approach for each case. ${ }^{135,136,147,148}$ Table 5 shows the most relevant aspects to be considered in this disease.

\section{REFERENCES}

1. Hohlfeld P, Forestier F, Kaplan C, Tissot C, et al. Fetal thrombocytopenia: a retrospective survey of 5.194 fetal blood samplings. Blood. 1994; 84(6):1851-6.

2. Uhrynowska M, Maslanka K, Zupanska B. Neonatal thrombocytopenia: incidence, serological and clinical observations. Am J Perinatol. 1997; 14(7):415-8.

3. Dreyfus M, Kaplan C, Verdy E, Schlegel N, et al. Frequency of immune thrombocytopenia in newborns: a prospective study. Immune Thrombocytopenia Working Group. Blood. 1997; 89(12):4402-6.

4. Sainio S, Jarvenpaa AL, Renlund M, Riikonen S, et al. Thrombocytopenia in term infants: a population-based study. Obstet Gynecol. 2000; 95(3):441-6.

5. Mehta P, Vas a R, Neum ann L, Ka rpa tkin M . Thrombocytopenia in the high-risk infant. J Pediatr. 1980; 97(5):791-4.

6. Castle V, Andrew M, Kelton J, Giron D, et al. Frequency and mechanism of neonatal thrombocytopenia. J Pediatr. 1986; 108(5 Pt 1):749-55.

7. Oren H, Irken G, Oren B, Olgun N, et al. Assessment of clinical impact and predisposing factors for neonatal thrombocytopenia. Indian J Pediatr. 1994; 61(5):551-8.

8. Andrew M, Vegh P, Caco C, Kirpalani H, et al. A randomized, controlled trial of platelet transfusions in thrombocytopenic premature infants. J Pediatr. 1993; 123(2):285-91.

9. Baer VL, Lambert DK, Henry E, Christensen RD. Severe thrombocytopenia in the NICU. Pediatrics. 2009; 124(6):e1095-100.

10. StanworthSJ, ClarkeP, Watts T, BallardS, etal. Prozspective, observational study of outcomes in neonates with severe thrombocytopenia. Pediatrics. 2009; 124(5):e826-34.

11. Von Lindern JS, Van den Bruele T, Lopriore E, Walther FJ. Thrombocytopenia in neonates and the risk of intraventricular hemorrhage: a retrospective cohort study. BMC Pediatr. 2011; 11:16.

12. Von Lindern JS, Hulzebos C, Bos A, Brand A, et al. Thrombocytopaenia and intraventricular haemorrhage in very premature infants: a tale of two cities. Arch Dis Child Fetal Neonatal Ed. 2012; 97(5):F348-52.

13. Gunnink SF, Vlug R, Fijnvandraat K, Van der Bom JG, et al. Neonatal thrombocytopenia: etiology, management and outcome. Expert Rev Hematol. 2014; 7(3):387-95.

14. Rodeghiero F, Stasi R, Gernsheimer T, Michel M, et al. Standardization of terminology, definitions and outcome criteria in immune thrombocytopenic purpura of adults and children: report from an international working group. Blood. 2009; 113(11):2386-93.

15. Ablin AR, Kushner JH, Murphy A, Zippin C. Platelet enumeration in the neonatal period. Pediatrics. 1961; 28:822-4.

16. Abali AJ, Puapondh Y, Desposito F. Platelet counts in thriving premature infants. Pediatrics. 1968; 42(4):685-9.

17. Sell EJ, Corrigan JJ Jr. Platelet counts, fibrinogen concentration, and factor $\mathrm{V}$ and factor VIII levels in healthy infants according togestational age. J Pediatr. 1973;82(6):102832.

18. Burrows RF, Kelton JG. Fetal thrombocytopenia and its relation to maternal thrombocytopenia. N Engl JMed. 1993; 329(20):1463-6.

19. Roberts I, Murray NA. Neonatal thrombocytopenia: causes and management. Arch Dis Child Fetal Neonatal Ed. 2003; 88(5):F359-64.

20. Christensen RD, Paul DA, Sola-Visner MC, Baer VL. Improving platelet transfusion practices in the neonatal intensive care unit. Transfusion. 2008; 48(11):2281-4.

21. Cremer M, Weimann A, Szekessy D, Hammer H, et al. Low immature platelet fraction suggests decreased megakaryopoiesis in neonates with sepsis or necrotizing enterocolitis. J Perinatol. 2013; 33(8):622-6.

22. Kulshrestha M, Sola-Visner M, WidnessJA, Veng-Pedersen $\mathrm{P}$, et al. Mathematical model of platelet turnover in thrombocytopenic and nonthrombocytopenic preterm neonates. Am J Physiol Heart Circ Physiol. 2015; 308(1):H6873.

23. Cremer M, Sallmon H, Kling PJ, Buhrer C, et al. Thrombocytopenia and platelet transfusion in the neonate. Semin Fetal Neonatal Med. 2016; 21(1):10-8.

24. Cines DB, Dusak B, Tomaski A, Mennuti M, et al. Immune thrombocytopenia and pregnancy. N Engl J Med. 1982; 306(14):826-31.

25. Cook RL, Miller RC, Katz VL, Cefalo RC. Immune thrombocytopenic purpura in pregnancy: a reappraisal of management. Obstet Gynecol. 1991; 78(4):578-83.

26. Wanachiwanawin W, Chansung K, Visudhiphan S, Piankijagum A. Outcomes of pregnancy in adultidiopathic thrombocytopenic purpura. J Med Assoc Thai. 1992; 75(10):584-90.

27. Hwa HL, Chen RJ, Chen YC, Wang TR, et al. Maternal and fetal outcome of pregnant women with idiopathic thrombocytopenic purpura: retrospective analysis of 25 pregnancies. J Formos Med Assoc. 1993; 92(11):957-61.

28. Al-Mofada SM, Osman ME, Kides E, al-Momen AK, et al. Risk of thrombocytopenia in the infants of mothers with idiopathic thrombocytopenia. Am J Perinatol. 1994; 11(6):423-6.

29. Sharon R, Tatarsky I. Low fetal morbidity in pregnancy associated with acute and chronic idiopathic thrombocytopenic purpura. Am J Hematol. 1994; 46(2):8790.

30. Sainio S, Joutsi L, Jarvenpaa AL, Kekomaki R, et al. Idiopathic thrombocytopenic purpura in pregnancy. Acta Obstet Gynecol Scand. 1998; 77(3):272-7.

31. Webert KE, Mittal R, Sigouin C, Heddle NM, et al. A retrospective 11-year analysis of obstetric patients with idiopathic thrombocytopenic purpura. Blood. 2003; 102(13):4306-11.

32. Samuels P, Bussel JB, Braitman LE, Tomaski A, et al. Estimation of the risk of thrombocytopenia in the offspring of pregnant women with presumed immune thrombocytopenic purpura. N Engl J Med. 1990;323(4):22935.

33. Karpatkin M, Porges RF, Karpatkin S. Platelet counts in infants of women with autoimmune thrombocytopenia. 
Effect of steroid administration to the mother. $N$ Engl J Med. 1981; 305(16):936-9.

34. Tchernia G, Morel-Kopp MC, Yvart J, Kaplan C. Neonatal thrombocytopenia and hidden maternal autoimmunity. $\mathrm{Br}$ J Haematol. 1993; 84(3):457-63.

35. OskiFA, NaimanJW.Problemas Hematológicosen el Recién Nacido. Buenos Aires: Panamericana; 1982.Págs.188-237.

36. Burrows RF, Kelton JG. Low fetal risks in pregnancies associated with idiopathic thrombocytopenic purpura. Am Obstet Gynecol. 1990; 163(4 Pt 1):1147-50.

37. Burrows RF, Kelton JG. Perinatal thrombocytopenia. Clin Perinatol. 1995; 22(3):779-801.

38. Valat AS, Caulier MT, Devos P, Rugeri L, et al. Relationships between severe neonatal thrombocytopenia and maternal characteristics in pregnancies associated with autoimmune thrombocytopenia. Br J Haematol. 1998; 103(2):397-401.

39. Van der Lugt NM, Van Kampen A, WaltherFJ, Brand A, etal. Outcome and management in neonatal thrombocytopenia due to maternal idiopathic thrombocytopenic purpura. Vox Sang. 2013; 105(3):236-43.

40. Kawaguchi K, Matsubara K, Takafuta T, Shinzato I, et al. Factors predictive of neonatal thrombocytopenia in pregnant women with immune thrombocytopenia. Int $J$ Hematol. 2014; 9(5):570-6.

41. Hachisuga K, Hidaka N, Fujita Y, Fukushima K, et al. Can we predict neonatal thrombocytopenia in offspring of women with idiopathic thrombocytopenic purpura? Blood Res. 2014; 49(4):259-64.

42. Karakurt N, Uslu I, Albayrak C, Tomak L, et al. Neonates born to mothers with immune thrombocytopenia: 11 years experience of a single academic center. Blood Coagul Fibrinolysis. 2018; 29(6):546-50.

43. Kelton JG. Management of the pregnant patient with idiopathic thrombocytopenic purpura. Ann Intern Med. 1983; 99(6):796-800.

44. Ozkan H, Cetinkaya MC, Koksal N, Ali R, et al. Neonatal outcomes of pregnancy complicated by idiopathic thrombocytopenic purpura. J Perinatol. 2010; 30(1):38-44.

45. Bussel JB, Druzin ML, Cines DB, Samuels P. Thrombocytopeniain pregnancy.Lancet.1991;337(8735):251.

46. Chirico G, Duse M, Ugazio AG, Rondini G. High-dose intravenous gammaglobulin therapy for passive immune thrombocytopenia in the neonate. J Pediatr. 1983;103(4):6545.

47. Ballin A, Andrew M, Ling E, Perlman M, et al. High dose intravenous gamma-globulin therapy for neonatal autoimmune thrombocytopenia. J Pediatr. 1988;112(5):78992.

48. Kelton JG. Idiopathic thrombocytopenic purpura complicating pregnancy. Blood Rev. 2002; 16(1):43-6.

49. British Committee for Standard in Haematology General Haematology Task Force. Guidelines for the investigation and management of idiopathic thrombocytopenic purpura in adults, children and in pregnancy. Br J Haematol. 2003; 120(4):574-96

50. Pearson HA, McIntosh S. Neonatal thrombocytopenia. Clin Haematol. 1978; 7(1):111-22.

51. Di Maria H, Parnet Mathieu F, Rio di Maria D, Maigret $P$, et al. Treatment of a positive Rhesus $\mathrm{D}$ neonate born of a mother with idiopathic thrombocypenic purpura with anti-D immunoglobulins (Rh O). Arch Fr Pediatr. 1990; 47(2):125-7.

52. Gaedicke G, Cremer M, Meyer O, Salama A. A therapyrefractory neonatal auto-immune thrombocytopenia treated with anti-D. Eur J Pediatr. 2004; 163(3):183-4.
53. Ayromlooi J. A new approach to the management of immunologic thrombocytopenic purpura in pregnancy. Am J Obstet Gynecol. 1978; 130(2):235-6.

54. Andrew M, Kelton J. Neonatal thrombocytopenia. Clin Perinatol. 1984; 11(2):359-91.

55. Moise KJ Jr, Carpenter RJ Jr, Cotton DB, Wasserstrum N, et al. Percutaneous umbilical cord blood sampling in the evaluation of fetal platelet counts in pregnant patients with autoimmune thrombocytopenic purpura. Obstet Gynecol. 1988; 72(3 Pt 1):346-50.

56. Scioscia AL, Grannum PA, Copel JA, Hobbins JC. The use of percutaneous umbilical blood sampling in immune thrombocytopenic purpura. Am J Obstet Gynecol. 1988; 159(5):1066-8.

57. Christiaens GCML, Helmerhorst FM. Validity of intrapartum diagnosis of fetal thrombocytopenia. Am J Obstet Gynecol. 1987; 157(4 Pt 1):864-5.

58. Mueller-Eckhardt C, Kiefel V, Grubert A. High-dose IgG treatment for neonatal alloimmune thrombocytopenia. Blut. 1989; 59(1):145-6.

59. Berry SM, Leonardi MR, Wolfe HM, Dombrowski MP, et al. Maternal thrombocytopenia. Predicting neonatal thrombocytopenia with cordocentesis. J Reprod Med. 1997; 42(2):276-80.

60. Murray JM, Harris RE. The management of pregnant patient with idiopathic thrombocytopenic purpura. Am J Obstet Gynecol. 1976; 126(4):449-51.

61. SilverRM,BranchDW, ScottJR. Maternal thrombocytopenia in pregnancy: time for a reassessment. Am J Obstet Gynecol. 1995; 173(2):479-82.

62. Burrows RF, Kelton JG. Pregnancy in patients with idiopathic thrombocytopenic purpura: assessing the risk for the infant at delivery. Obstet Gynecol Surv. 1993; 48(12):7818.

63. Vazquez L, Donato H. Trastornos hematológicos secundarios a patología materna. In Donato H, Rapetti MC (eds.). Hematología Neonatal. Buenos Aires: Fundasap; 2007.Pages 309-36.

64. Watson R, Kang J E, May M, Kickler T, et al. Thrombocytopenia in the neonatal lupus syndrome. Arch Dermatol. 1988; 124(4):560-3.

65. Su CT, Huang CB, Chung MY. Neonatal lupus erythematosus in association with anti-RNP antibody: a case report. Am J Perinatol. 2001; 18(8):421-6.

66. Provost T, Watson R, Gammon W, Radowsky M, et al. The neonatal lupus syndrome associated with U(1)RNP (nRNP) antibodies. N Engl J Med. 1987; 316(18):1135-8.

67. Provost T, Watson R, Gaither K, Harley J. The neonatal lupus erythematosus syndrome. J Rheumatol. 1987; 14(Suppl 13):199-205.

68. Glantz J, Roberts D. Pregnancy complicated by thrombocytopenia secondary to human immunodeficiency virus infection. Obstet Gynecol. 1994; 83(5 Pt 2):825-7.

69. DeVauz LO, Lahey ME, Mauer AM. Neonatal and maternal thrombocytopenic purpura due to quinine. Pediatrics. 1957; 19(1):84-7.

70. Shulman NR. Immunoreactions involving platelets. I. A steric and kinetic model for formation of a complex from a human antibody, quinidine as a haptene, and platelets; and for fixation of complement by the complex. J Exp Med. 1958; 107(5):665-90.

71. Mueller-Eckhardt C, Becker T, Weisheitz M, Witz C, et al. Neonatal alloimmune thrombocytopeniadue to fetomaternal Zwb incompatibility. Vox Sang. 1986; 50(2):94-6.

72. Blanchette VS, Peters MA, Pegg-Feige K. Alloimmune 
thrombocytopenia. Review from a neonatal intensive care unit. Curr Stud Hematol Blood Transfus. 1986; 52:87-96.

73. Mueller-Eckhardt C, Kiefel V, Grubert A, Kroll H, et al. 348 cases of suspected neonatal alloimmune thrombocytopenia. Lancet. 1989; 1(8634):363-6.

74. Burrows RE, Kelton JG. Incidentally detected thrombocytopenia in healthy mothers and their infants. N Engl J Med. 1988; 319(3):142-5.

75. Blanchette VS, Chen L, De Friedberg ZS, Hogan VA, et al. Alloimmunization to the PlA1 platelet antigen: results of a prospective study. Br J Haematol. 1990; 74(2):209-15.

76. Taaning E, Skibsted L. The frequency of platelet alloantibodies in pregnant women and the occurrence and management of neonatal alloimmune thrombocytopenic purpura. Obstet Gynecol Surv. 1990; 45(8):521-5.

77. Pearson HA, Shulman NR, Marder VJ, Cone TE Jr. Isoimmune neonatal thrombocytopenic purpura. Clinical and therapeutic considerations. Blood. 1964; 23:154-77.

78. Shulman NR, Marder VJ, Hiller MC, Collier EM. Platelet and leukocyte isoantigens and their antibodies: serologic, physiologic and clinical studies. Prog Hematol. 1964; 4:222304.

79. Reznikoff-Etievant MF. Management of alloimmune neonatal and antenatal thrombocytopenia. Vox Sang. 1988; 55(4):193-201.

80. Harrington WJ, Sprague CC, Minnich V, Moore CV, et al. Immunologic mechanisms in idiopathic and neonatal thrombocytopenic purpura. Ann Intern Med. 1953; 38(3):43369.

81. Von dem Borne AE, Von Reisz E, Verheught FW, Ten Cate JW, et al. Baka, a new platelet-specific antigen involved in neonatal alloimmune thrombocytopenia. Vox Sang. 1980; 39(2):113-20.

82. Von dem Borne AEG, Van Leerwen EF, Von Riesz LE, Van Boxtel CJ, et al. Neonatal alloimmune thrombocytopenia: Detection and characterization of the responsible antibodies by the platelet immunofluorescence test. Blood. 1981; 57(4):649-56.

83. Mueller-EckhardtC, Marks HJ, Baur MP, Mueller-Eckhardt G. Immunogenetic studies of the platelet-specific antigen PlA1(Zw(a)). Immunobiology. 1982; 160(5):375-81.

84. De Alarcón P. Newborn platelet disorders. In: De Alarcón P, Werner E (eds.). Neonatal Hematology. Cambridge: Cambridge University Press; 2005.Pages 187-253.

85. Evans DI. Immune amegakaryocytic thrombocytopenia of the newborn: association with anti-HLA-A2. J Clin Pathol. 1987; 40(3):258-61.

86. Bizzaro N, Dianese G . Neonatal alloimmune amegakaryocytosis: case report. Vox Sang. 1988; 54(2):112-4.

87. Warwick RM, Vaughan J, Murray N, Lubenko A, et al. In vitro culture of colony forming unit-megakaryocyte (CFUMK) in fetal alloimmune thrombocytopenia. Br J Haematol. 1994; 88(4):874-7.

88. Skogen B, Husebekk A, Killie MK, Kjeldsen-Kragh J. Neonatal alloimmune thrombocytopenia is not what it was. A lesson learned from a large prospective screening and intervention program. Scand J Immunol. 2009; 70(6):531-4.

89. Homans A. Thrombocytopenia in the neonate. Pediatr Clin North Am. 1996; 43(3):737-56.

90. Bussel J. Diagnosis and management of the fetus and neonate with alloimmune thrombocytopenia. J Thromb Haemost. 2009; 7(suppl 1):253-7.

91. Peterson JA, McFarland JG, Curtis BR, Aster RH. Neonatal alloimmune thrombocytopenia: pathogenesis, diagnosis and management. Br J Haematol. 2013; 161(1):3-14.
92. Deaver JE, Leppert PC, Zaroulis CG. Neonatal alloimmune thrombocytopenic purpura. Am J Perinatol. 1986; 3(2):12731.

93. Blanchette VS. Neonatal alloimmune thrombocytopenia: a clinical perspective. Curr Stud Hematol Blood Transfus. 1988; 54:112-26.

94. Ghevaert C, Campbell K, Walton J, Smith GA, et al. Management and outcome of 200 cases of fetomaternal alloimmune thrombocytopenia. Transfusion. 2007; 47(5):90110.

95. Kjeldsen-Kragh J, Killie MK, Tomter G, Golebiowska E, et al. A screening and intervention program aimed to reduce mortality and serious morbidity associated with severe neonatal alloimmune thrombocytopenia. Blood. 2007; 110(3):833-9.

96. Kamphuis MM, Paridaans NP, Porcelijn L, Lopriore E, et al. Incidence and consequences of neonatal alloimmune thrombocytopenia: a systematic review. Pediatrics. 2014; 133(4):715-21.

97. Zalneraitis EL, Young RSK, Krishnamoorthy KS. Intracranial hemorrhage in utero as a complication of isoimmune thrombocytopenia. J Pediatr. 1979; 95(4):611-4.

98. Blanchette VS, McFarland JG, Freedman J. 426: Very early thrombocytopenia in neonatal alloimmune thrombocytopenic purpura. Am J Obstet Gynecol 1993; 168(1):414

99. Bonacossa IA, Jocelyn LJ. Alloimmune thrombocytopenia of the newborn: neurodevelopmental sequelae. Am JPerinatol. 1996; 13(4):211-5.

100.Mao CY, Guo JW, Chituwo BM. Intraventricular haemorrhage and its prognosis, prevention and treatment in term infants. J Trop Pediatr. 1999; 45(4):237-40.

101.Bussel JB, Tanli S, Peterson HC. Favorable neurological outcome in 7 cases of perinatal intracranial hemorrhage due to immune thrombocytopenia. Am J Pediatr Hematol Oncol. 1991; 13(2):156-9.

102.Sharif U, Kuban A. Prenatal intracranial hemorrhage and neurologic complicationsinalloimmunethrombocytopenia. J Child Neurol. 2001; 16(11):838-42.

103.Kjaer M, Bertrand G, Backchoul T, Massey E, et al. Maternal HPA-1a antibody level in predicting the severity of fetal/ neonatal alloimmune thrombocytopenia: a systematic review. Vox Sang. 2019; 114(1):79-94.

104.Bussel JB, Sola-Visner M. Current approaches to the evaluation and management of the fetus and neonate with immune thrombocytopenia. Semin Perinatol. 2009;33(1):3542.

105.Carr R, Kelly AM, Williamson LM. Neonatal thrombocytopenia and platelet transfusion - A UK perspective. Neonatology. 2015; 107(1):1-7.

106.KaplanC, NiH,FreedmanJ. Alloimmunethrombocytopenia. In: Michelson AD (eds.). Platelets. $3^{\text {rd }}$ ed. San Diego, USA: Elsevier / Academic Press; 2013.Pages 953-70.

107.Zdravic D, Yougbare I, Vadasz B, Li C, et al. Fetal and neonatal alloimmune thrombocytopenia. Semin Fetal Neonat Med. 2016; 21(1):19-27.

108.Adner MM, Fisch GB, Starobin GS, Aster RH. Use of "compatible" platelet transfusions in treatment of congenital isoimmune thrombocytopenic purpura. $N E n g l$ J Med. 1969; 280(5):244-7.

109.Vain NE, Bedros AA. Treatment of isoimmune thrombocytopenia of the newborn with transfusion of maternal platelets. Pediatrics. 1979; 63(1):107-9.

110.Bertrand G, Kaplan C. How do we treat fetal and neonatal alloimmune thrombocytopenia? Transfusion. 2014; 
54(7):1698-703.

111.Lucas GF, Bendukidize N. HPA-1a(-), 5b(-) platelets for use in neonatal alloimmune thrombocytopenia - from "Cinderella" product to standard component. Transfus Med. 2014; 24(2):127-9.

112.Winkelhorst D, Oepkes D, Lopriore E. Fetal and neonatal alloimmune thrombocytopenia: evidence based antenatal and postnatal management strategies. Expert Rev Hematol. 2017; 10(8):729-37.

113.WinkelhorstD, Oostweegel M, Porcelijn L, Niddelburg RA, et al. Treatment and outcomes of fetal/neonatal alloimmune thrombocytopenia: a nationwide cohort study in newly detected cases. Br J Haematol. 2019; 184(6):1026-9.

114.Lieberman L, Greinacher A, Murphy MF, Bussel J, et al. Fetal and neonatal alloimmune thrombocytopenia: recommendations for evidence-based practice, an international approach. Br J Haematol. 2019; 185(3):549-62.

115.McIntosh S, O'Brien RT, Schwartz AD, Pearson HA. Neonatal isoimmune purpura: response to plateletinfusion. J Pediatr. 1973; 82(6):1020-7.

116.Galea P, Patrick MJ, Goel KM. Isoimmune neonatal thrombocytopenic purpura. Arch Dis Child. 1981;56(2):1125.

117.Katz J, Hodder FS, Aster RS, Bennetts GA, et al. Neonatal isoimmune thrombocytopenia: the natural course and management and the detection of maternal antibody. Clin Pediatr (Phila). 1984; 23(3):159-62.

118.Espinoza JP, Caradeux J, Norwitz ER, Illanes SE. Fetal and neonatal alloimmune thrombocytopenia. Rev Obstet Gynecol. 2013; 6(1):e15-21.

119.Bakchoul T, Bassler D, Heckmann M, Thiele T, et al. Management of infants born with severe neonatal alloimmune thrombocytopenia: the role of platelet transfusions and intravenousimmunoglobulin. Transfusion. 2014; 54(3):640-5.

120.Bertrand G, Blouin L, Boehlen F, LevineE, et al. Management of neonatal thrombocytopenia in a context of maternal antiplateletalloimmunization: Expert opinion of the Frenchspeaking working group. Arch Pediatr. 2019; 26(3):191-7.

121.Sidiropoulos D, Straume B. The treatment of neonatal isoimmune thrombocytopenia with intravenous immunoglobin (IgG i.v.). Blut. 1984; 48(6):383-6.

122.Bassler D, Greinacher A, Okascharoen C, Klenner A, et al. A systematic review and survey of the management of unexpected neonatal alloimmune thrombocytopenia. Transfusion. 2008; 48(1):92-8.

123.Tiller H, Kamphuis MM, Flodmark O, Papadogiannakis N, et al. Fetal intracranial haemorrhages caused by fetal and neonatal alloimmune thrombocytopenia: an observational cohort study of 43 cases from an international multicenter registry. BMJ Open. 2013; 3(3):e002490.

124.Ghevaert C, Herbert N, Hawkins L, Grehab N, et al. Recombinant HPA-1a antibody therapy for treatment of fetomaternal alloimmune thrombocytopenia: proof of principle in human volunteers. Blood. 2013; 122(3):313-20.

125.Bakchoul T, Greinacher A, Sachs UJ, Krautwurst A, et al. Inhibition of HPA-1a alloantibody-mediated platelet destruction by a deglycosylated anti-HPA-1a monoclonal antibody in mice: toward targeted treatment of fetalalloimmune thrombocytopenia. Blood. 2013; 122(3):321-7.

126.Salomon O, Rosenberg N. Predicting risk severity and response of fetal neonatal alloimmune thrombocytopenia. Br J Haematol. 2013; 162(3):304-12.

127.Eksteen M, Tiller H, Averina M, Heide G, et al. Characterization of a human platelet antigen-1a-specific monoclonal antibody derive from a B cell from a woman alloimmunized in pregnancy. J Immunol. 2015; 194(12):575160.

128.Mennuti M, Schwarz RH, Gill F. Obstetric management of isoimmune thrombocytopenia. Am J Obstet Gynecol. 1974; 118(4):565-6.

129.Sitarz A, Driscoll JM, Wolff JA. Management of isoimmune neonatal thrombocytopenia. Am J Obstet Gynecol. 1976; 124(1):39-42.

130.Kaplan C, Morel-Kopp MC, Clemenceau S, Daffos F, et al. Fetal and neonatal alloimmune thrombocytopenia: current trends in diagnosis and therapy. Transfus Med. 1992; 2(4):265-71.

131.Letsky EA, Greaves M. Guidelines on the investigation and management of thrombocytopenia in pregnancy and neonatal alloimmune thrombocytopenia. Maternal and Neonatal Haemostasis Working Party of the Haemostasis and Thrombosis Task Force of the British Society of Haematology. Br J Haematol. 1996; 95(1):21-6.

132.Bussel J, Kaplan C. The fetal and neonatal consequences of maternal alloimmune thrombocytopenia. Baillieres Clin Haematol. 1998; 11(2):391-408.

133. Murphy MF, Pullon HW, Metcalfe P, Chapman JF, et al. Management of fetal alloimmune thrombocytopenia by weekly in utero platelet transfusions. Vox Sang. 1990; 58(1):45-9.

134.Murphy MF, Waters AH, Doughty HA, Hambley H, et al. Antenatal management of fetomaternal alloimmune thrombocytopenia: report of 15 affected pregnancies. Transfus Med. 1994; 4(4):281-92.

135.Kanhai HH, Porcelijn L, Van Zoeren D, Klumper F, et al. Antenatal care in pregnancies at risk of alloimmune thrombocytopenia: report of 19 cases in 16 families. Eur J Obstet Gynecol Reprod Biol. 1996; 68(1-2):67-73.

136.Sainio S, Teramo K, Kekomäki R. Prenatal treatment of severe fetomaternal alloimmune thrombocytopenia. Transfus Med. 1999; 9(4):321-30.

137. Overton TG, Duncan KR, Jolly M, Letsky E, et al. Serial aggressive platelet transfusion for fetal alloimmune thrombocytopenia: platelet dynamics and perinatal outcome. Am J Obstet Gynecol. 2002; 186(4):826-31.

138.Kroll H, Kiefel V, Giers G, Bald R, etal. Maternal intravenous immunoglobulin treatment does not prevent intracranial hemorrhage in fetal alloimmune thrombocytopenia. Transfus Med. 1994; 4(4):293-6.

139.Bussel JB, Berkowitz R, McFarland JM, Lynch L, et al. Antenatal treatment of neonatal alloimmune thrombocytopenia. N Engl J Med. 1988; 319(21):1374-8.

140.Mir N, Samson D, House MJ, Kovar IZ. Failure of antenatal high-dose immunoglobulin to improve fetal platelet count in neonatal allo-immune thrombocytopenia. Vox Sang. 1988; 55(3):188-9.

141.Nicolini U, Tannirandon Y, González P, Fisk NM, et al. Continuing controversy in alloimmune thrombocytopenia: Fetal hyperimmunoglobulinemia fails to prevent thrombocytopenia. Am J Obstet Gynecol. 1990; 163(4 Pt 1):1144-6.

142.Kaplan C, Murphy MF, Kroll H, Waters AH. Feto-maternal alloimmune thrombocytopenia: antenatal therapy with IVIG and steroids-more questions than answers. European Working Group of FMAIT. Br J Haematol. 1998; 100(1):62-5.

143.Lynch L, Bussel JB, McFarland JG, Chitkara U, et al. Antenatal treatment of alloimmune thrombocytopenia. Obstet Gynecol. 1992; 80(1):67-71.

144.Spencer JA, Burrows RF. Feto-maternal alloimmune 
e214 / Arch Argent Pediatr 2021;119(3):e202-e214 / Review

thrombocytopenia: a literature review and statistical analysis. Aust NZ J Obstet Gynecol. 2001; 41(1):45-55.

145.Bertrand G, Drame M, Martageix C, Kaplan C. Prediction of the fetal status in noninvasive management of alloimmune thrombocytopenia. Blood. 2011; 117(11):3209-13.

146.Winkelhorst D, Murphy M, Greinacher A, Shehata T, et al. Antenatal management in fetal and neonatal alloimmune thrombocytopenia: a systematic review. Blood. 2017;
129(11):1538-47.

147.Dickinson JE, Marshall LR, Phillips JM, Barr AL. Antenatal diagnosis and management of fetomaternal alloimmune thrombocytopenia. Am J Perinatol. 1995; 12(5):333-5.

148.Blanchette VS, Johnson J, Rand M. The management of alloimmune neonatal thrombocytopenia. Baillieres Best Pract Res Clin Haematol. 2000; 13(3):365-90. 